\title{
Maintenance model based on multi agent system improving the performance to a total quality management

\author{
D. Helmi ${ }^{1}$, M. Radouani ${ }^{2}$, B. El fahime ${ }^{3}$, S.A. Kamel kaya ${ }^{4}$
}

Equipe IMSM - Laboratoire de recherche MMC ENSAM - My Ismail University Meknès, Morocco

1d.helmi@umi.ac.ma

${ }^{2}$ m.radouani@ensam-umi.ac.ma

3b.elfahime@ensam-umi.ac.ma

${ }^{4}$ kayasak2000@yahoo.fr

\section{ABSTRACT}

Manufacturers recognize that production systems have no value if the production equipment is unreliable. Nowadays industrial maintenance, strategic business function is evolving. It is inter-related to the development of knowledge and technology, the development of new business methods well as the need to reduce costs. It should not only ensure the proper functioning of equipment but also to continually improve their performance, and enhance their lives. All these factors play havoc not only the modes of organization of the maintenance function but also the activities of actors who operate in this area.

Our article focuses on "the management systems and processes" main pillar of Total Quality Management, whose base rests on the multi-agent modelling.

\section{Indexing terms/Keywords}

Total Quality Management; Multi-Agents Systems; Industrial Maintenance; Performance; PDCA.

\section{Council for Innovative Research}

Peer Review Research Publishing System

\section{Journal: International Journal of Management \& Information Technology}

Vol. 9, No. 2

editor@cirworld.com

www.cirworld.com, member.cirworld.com 


\section{INTRODUCTION}

In today's competitive environment, companies can not simply "doing well" and "reduce dysfunctions". Their sustainability requires innovation in the sense of providing ever more appropriate to market new answers and generating cash flow. By the strategic role that is devolved, industrial maintenance keeps the buildings, equipment and tooling in physical conditions that favour their optimal use. When we deploy the necessary efforts to maintain a suitable operation, we have reaped great benefits such as:

- A better use of resources;

- An increase capacity and productivity;

- A satisfactory profitability in:

- customer service,

- satisfaction request,

- delivery times,

- a machine downtime,

- unplanned production stops.

- A reduction in costs associated with downtime.

Continuous improvement of all these parameters represents a substantial advantage. However, industrial maintenance often remains dependent on organizational modes and closely linked to the expertise of maintenancier whatever their capacity for problems solving, and it is rarely systematized as a whole, which makes it vulnerable to the human factor skills and professional practices.

In this respect, Deming stated the rule of "85/15", namely, that the effectiveness of the employee is determined to $85 \%$ by the system in which they work, and only $15 \%$ depends on his skills [1]. Thus, the improved results over the long term should focus on the process and eliminate Muda (waste) to the extent that their elimination:

- Helps avoid waste and to act according to the principle of "right first time".

- Leads to reduced costs and become lasting through the definition, implementation and compliance with the operational standards.

This mind-set of the process control, itself resulting from the control of used various parameters and processes. The notion of control requires not only maintaining a given level of performance, but also its progress (progress towards a desired level of performance or continuous improvement). Otherwise-known, master, is to guarantee the reliability, maintainability and safety of the process.

In this perspective, we propose a model that provides maintenance and disposal of MUDA in how to use the resources (Manpower, Machine, Material, and Method) and operating in conversational time.

\section{MULTI-AGENT MODELLING AND INDUSTRIAL PERFORMANCE INTERRELATION}

Performance, as well as several concepts such as quality, risks and Multi-Agent Systems, covers a large number of definitions depending on sector and perspectives.

Today, theoretical models who are unidimensional are exceeded, especially in the industrial field. It becomes a multidimensional concept according to actors or situations may vary. In sum, the performance approach must be comprehensive. One of the interesting approaches in the sense of an integrator model of organizational performance which states that, for sustainability, an organization must maintain four functions "Figure 1".

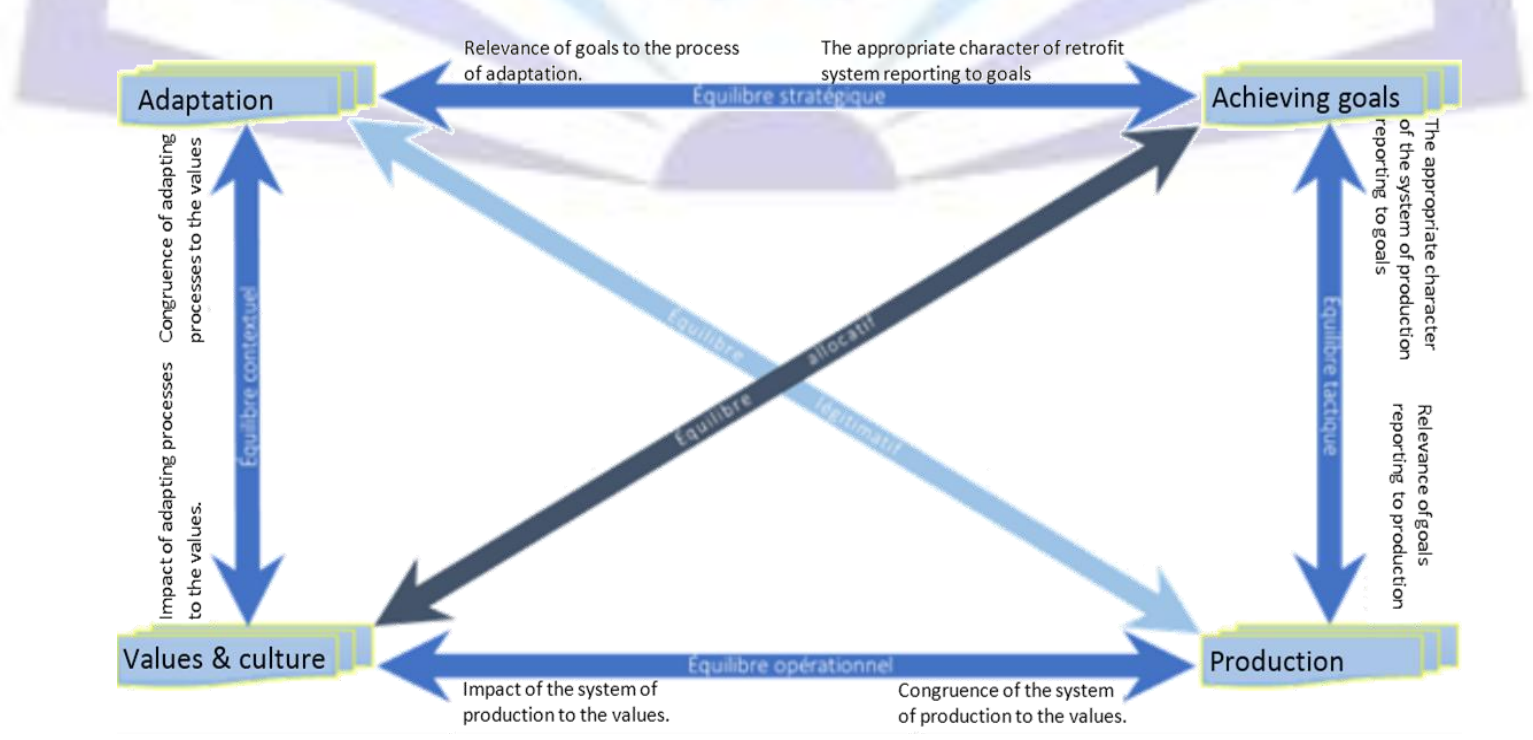

Fig 1: Conceptual framework for the analysis of the companies performance 
Moreover, the purpose of each function is to meet the needs of one or more internal or external customers. If it is intended for internal customers, it should be evaluated as to the added value it brings to the external client. If it is addressed for internal customers, it should be evaluated as to the added value it brings to the external client. The multi-agent modelling seems able to represent problems with several solving methods, multiple perspectives and / or different solvers. In our case, it is a computer model linking all rings maintenance chain, creating value, management of replacement parts for the deployment of appropriate maintenance and development of a scorecard of performance industrial, which requires the use the technical evaluation of production tools, their failures and risk analysis.

A computerized maintenance systemic model, operating in real time, based on the concept of SMA as a support decision aid.

The terms "agent" and "Multi-agent" are relatively new and until now their definitions do not unanimous [2]. However, they converge to mean that SMA consists of autonomous computing entities called agents perceiving and acting in an environment.

SMA evolves through the interactions of its agents, and can be structured according to a predefined or organization emerged. For the properties of SMA are described across four axes on which breaks down the complexity of a system are:

- Individual Complexity (internal architecture of agents).

- Functional heterogeneity and emergence (structure dynamic interaction).

- Specification and interaction structures by organizational approaches.

The interactions between agents are the lifeblood of the global dynamics of a SMA. It should be emphasized that an essential property of SMA is to present a dynamic interaction structure [3]: the freedom of action of an agent is not only in the definition of "content" of his actions but is also in definition of entities to which it directs his actions. It is this ability of agents to reshape the structure of the interaction system that allows them to adapt themselves with new situations and make emerging collective behaviour [4].

More especially as the nature of interactions may be more or less sophisticated, simple interactions of physical type of interactions carried by structured languages.

Regarding the organization of MAS, it refers to an intermediate level of description between the agent and the system which realizes a form of structuring the behaviour of agents and their interactions.

The representation of organizational agents in a MAS takes many forms and names according to the organization of SMA is implicit or explicit, static or dynamic, emergent or imposed by the designer.

\section{ARCHITECTURE OF THE MAINTENANCE FUNCTION}

The elaborate architecture borrows the quality process is a Dynamics of Change "Figure 2". It is based on the cycle of W. Shewhart Plan-Do-Check-Act (PDCA) [5] which becomes with W. E. Deming a genuine management tool for any company.

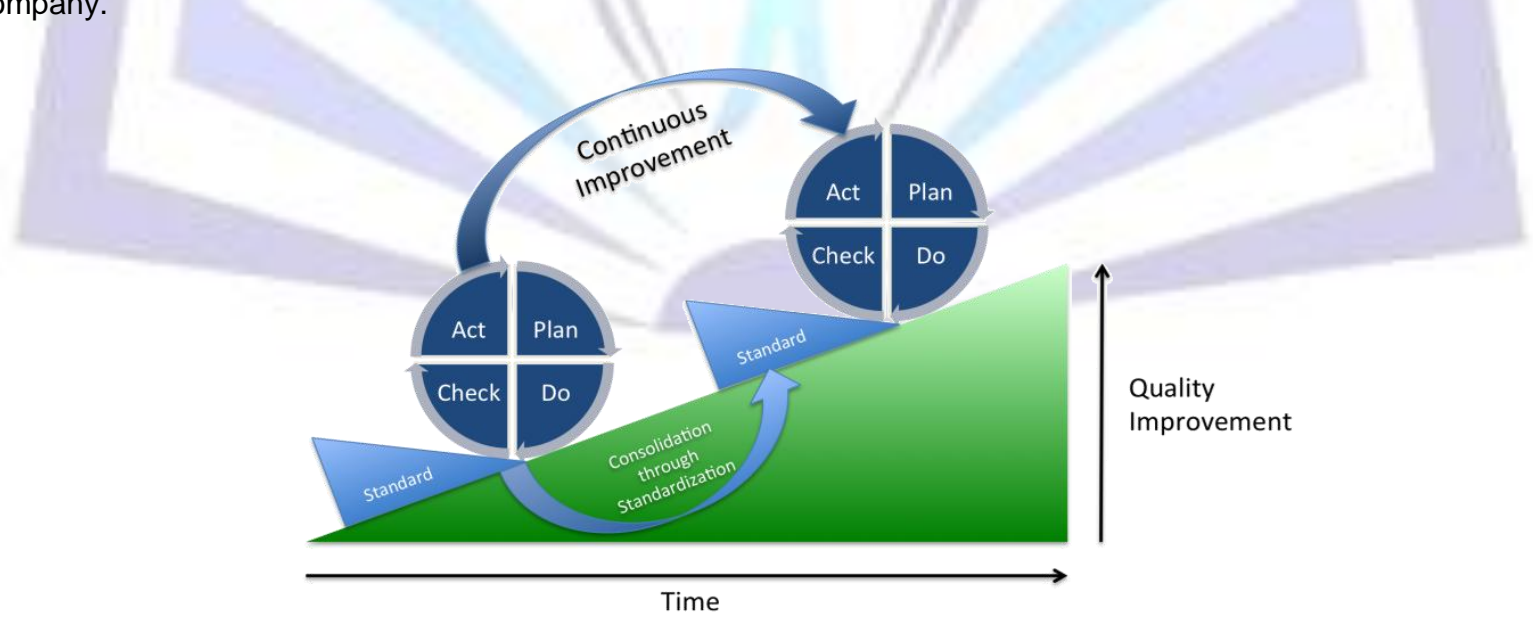

Fig 2: Dynamic approach of the quality

This approach recommends that companies should study and understand their production processes or services with ever greater precision. If the company wants to divide the system into different blocks for analytical uses, it must also consider "internal customers" which implement the processes required. The quantitative analysis of the processes is also very important. Companies must examine them thoroughly before and after the changes, by repeating each time the PDCA cycle approach. 
The PDCA cycle includes four stages, namely: stabilize the process, apply the standard debugged, vigorously respect the standard and improve the standard. It's the improvement through time which leads constantly to performance "Figure 3".

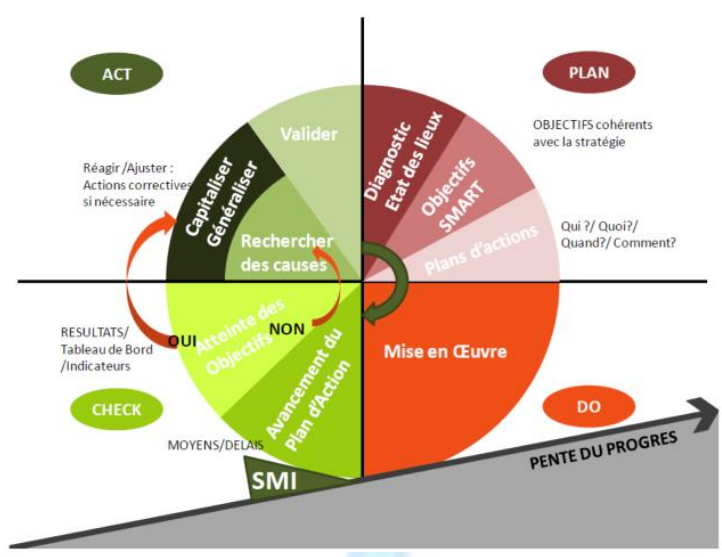

Fig 3: Towards a total quality management.

The process of realizing the continuous improvement of quality is a perpetual cycle "Figure 4 " that is based on five phases.

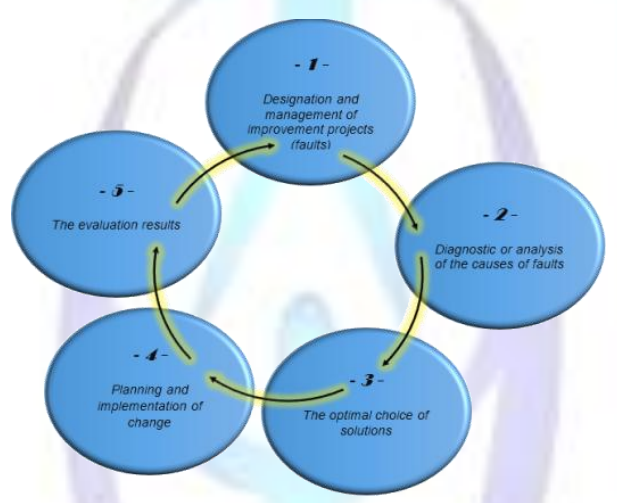

Fig 4: The process of realizing the continuous improvement of quality.

We focus on continuous improvement of the quality of the maintenance function. But not the quality of the product or service as is the case with its inventor. Maintenance is the availability, reliability, maintainability and safety of production tools while avoiding the maximum wastage of resources devoted to this structure.

Our architecture consists of several steps each of them is provided by an entity and / or agent "Figure 5". The Information flows provided by each entity and / or agent are routinely disseminated through the proposed architecture in all phases. This will allow update in real time all the indicators related to the efficiency of maintenance (XP X60 020) [6].

This is a guarantee a continuous updating of the database and the insurance support for a suitable decision.

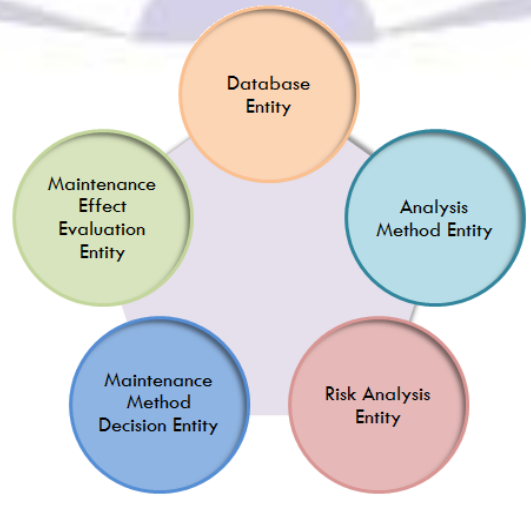

Fig 5: Architecture of Industrial Maintenance. 


\section{Database Entity: Documentation \& BDD}

In our case, the entity "Data base" embodies the documentation system that capitalizes on information and decisions. It is both the last and the first of the PDCA wheel. It is the last by receiving new indicators following the established experience and will be the first to use this new information and to consider the new state instead maintain or improve. This entity records, directly or indirectly through existing computer supports (transfer failures to different structures of the park via intranet for example), all scheduled stops or not of industrial park production lines that appeared along a given period of time while specifying their causes, their duration and the actions performed period.

This computer entity, considered as a raw database containing all the information needed by other agents (suppliers standards, technical specifications of equipment, indicators ...). In addition, it evaluates maintainability, availability, reliability and security of production tools while providing technical indicators such as the indicator of amount of interventions, the reliability indicator (Mean Time Between Failure), the indicator of competence (Mean Time To Repair), (MTBF + MTTR MTBF ), unavailability indicator, the indicator of maintenance costs of equipment and the indicator of maintenance impact.

\section{Analysis Method Entity}

It aims to determine a systems analysis approach that relies on inductive reasoning (causes, consequences) for the organized study of the causes, effects and criticality failures. It will identify functions, constraints of usage and environmental, parameters critics to bring under control and that many analyses are based such as AF, FMECA, AVA and risk management. It is made up two agents and an entity and that interact by coordination namely:

$>$ Agent diagram cause-effect

This diagram is a graphical method to analyse in depth a particular situation (the effect) to bring out all potentially connectable to the problem under study causes. This tree allows us to:

- $\quad$ structure a message,

- $\quad$ visualize a situation in order to bring up the key points,

- identify all possible causes of the effect of a problem,

- $\quad$ select cases to be given priority.

Cases are typically grouped into major categories. The categories typically include five factors:

- Materials, Machine, Man, Methods, Environment.

Sometimes it include eight factors by adding: Management-Money-Market.

$>$ Agent Failure Mode, Effects and Criticity Analysis

This agent identifies and examines methodically potential failures of the system, analysis of failure modes, their causes and their effects on the functioning of the whole. It should be noted that the entity EMECA must conduct to a functional analysis of the production tool. This is to identify the factors to be considered, their environment and their functions. This is a vital step to structure and conduct the subsequent step of failure analysis. Each is characterized by:

- $\quad$ Severity of the potential effect;

- Occurrence of the potential cause;

- Detection (efficiency of the monitoring system);

- Recovery (time, cost) to come back to a normal situation.

We then deduce the Risk Priority Number (RPN) is the product "S * $O$ * $D$ " or "S * $O$ * $D$ * R". The RPN will be used in the method for setting priorities among the actions to achieve and follow. The FMECA remains a preliminary an approach to:

- $\quad$ Design of experiment (DOE) to limit the number of "marginality" of a process,

- Develop control plans

- Anticipate problems related to any modification of processes (increased production, introduction of new equipment, processes ...).

Moreover, in the context of maintenance, the FMECA means is a perfect tool for collecting and axiomatize all information on observed failures, especially in the absence of the data historic. The experience of each entity may well be better capitalized and transmitted. It is also an effective tool for communication between the various entities / agents involved in equipment: methods and maintenance operators, new work methods and production operators, etc.

\section{Risk Analysis Entity}

The risk is not only from an actor of chain, but from a series of errors that accumulate. There is no use to aim for zero defects on one of the phases if there are significant failures at other levels. Any management of operational risks associated with the reporting of undesired events, periodicals ENS, analysis of the causes, identification and analysis of processes at risk, the estimation of the criticality of key risks.

The agent needs to have a methodological framework for realization of an estimated risk upstream of a decision (FD X50-252). [7] Similarly, ISO 31000 (principles and guidelines for the implementation of a process of risk management) 
intended to harmonize the process of risk management and definitions that are attached, give advice on setting implementation and maintenance of the management system and sensitize entities / agents to risk management [8].

\section{Maintenance Method Decision Entity}

In light of the results generated by other entities and / or agents in terms of the documentation, methods, evaluations, this agent is able to recommend the proper maintenance that respects the specifications and standards requirements providers, the technical condition of equipment (obsolescence, use) and the production constraints.

It aims to determine the policy of maintenance (corrective, preventive, predictive), inventory management of replacement parts, the procedures to implement the training of employees and upgrade financial feasibility studies and replacement of equipment. To allow him this role, the entity has different types of maintenance and their conditions of use by reference to the standard (NFX 60-010) [9].

\section{Maintenance Effect Evaluation Entity}

Experience feedback (REX) is essential to the effectiveness, efficiency, relevance and effectiveness. The modelling of the maintenance function is justified if and only if the technical indicators have improved. It becomes useful and exploitable provided it avoids a maximum waste of resources. Indeed, failures are production hollow and the opportunity to generate unproductive expenditures. The agent's role is to develop new performance indicators. It provides a state of equipment performance indicators: maintainability, reliability, availability and security.

\section{CONCLUSION}

The importance given to industrial management fact that Management of Total Quality is in extreme foreground of debates that falls under the research global performance. This recourse to the Total Quality Management is justified by the fact that managers believe hard a strong positive correlation between TQM and global business performance.

This article can be considered as an extension of previous work in this direction and may help us to understand the nature of the relationship that may exist between TQM - Industrial maintenance and global performance. Currently if the concepts of quality culture, cultural risks are sought by all, few studies link them to the concept of performance.

For future work, It should be emphasized that the measurement of the performance is in itself a factor in improving performance. This led us to develop (describe) a conceptual model combining some critical practices (salient) of TQM, modelling Multi-Agent and the maintenance function.

\section{REFERENCES}

[1] Kilian, C. The World of W. Edwards Deming, Second Edition, vol. TN: SPC Press, Knoxville, 1992.

[2] Theodoropoulos, G., Minson, R., Ewald, R. and Lees, M. Multi-Agent Systems: Simulation and Applications: CRC Press, 2009.

[3] FERRAND, N. De l'apport potentiel de la sociologie pour l'ingénierie des systèmes sociaux artificiels, journées de RocheBrune. Du collectif au social, 1996.

[4] Müller, J.P. Des systèmes autonomes aux systèmes multi-agents : interactions, émergence et systèmes complexes. Rapport présenté pour l'obtention de l'HDR, p. 582002.

[5] Shewhart, W.A. Les fondements de la maitrise de la qualité. Econimica, 1989.

[6] X. X60-020, Maintenance. Indicateurs de maintenance. ed, 08/1995.

[7] F. X. 50-252, Une démarche pour estimer ses risques, ed, 01/2007.

[8] Mazouni, M.H. Pour une Meilleure Approche du Management des Risques : De la Modélisation Ontologique du Processus Accidentel au Système Interactif d'Aide à la Décision, Doctorat, Institut National Polytechnique de Lorraine, 2008.

[9] NFX 60- 010, Vocabulaire de maintenance et de gestion des biens durables, ed. Paris: Afnor Gestion, 1984 p. 8.

\section{Author' biography with Photo}

Driss HELMI is currently a Ph.D. student within MMC laboratory in Moroccan National Higher School of Engineering (ENSAM Meknes - Moulay Ismail University, Morocco). His research activities concern Performance multidimensional systems management and industrial processes and Total Quality Management.

Mohammed RADOUANI is an associate professor at the National Higher School of Engineering (Crafts and Technologies, ENSAM Meknès - Moulay Ismail University, Morocco). He obtained his Ph.D. thesis in Mechanical Engineering from Prestigious training college for teachers and researchers in Technics (ENS of Cachan, University of Paris-south XI France, in 2003) and his Habilitation of supervising scientific research Dissertation from Faculty of Sciences-Meknès in 2009. His research work is dealing with specification and inspection of mechanical systems according to the ISO standards. He is also interested to products numerical engineering. 
Benaissa EL FAHIME is an associate professor at the National Higher School of Engineering (ENSAM Meknès - Moulay Ismail University, Morocco). He obtained his Ph.D. thesis in Mechanical Engineering from the - Faculty of Science and Technology of Fez. His research activities concern the representation of mechanical tolerances in the Bond Graph models of mechatronic systems.

After practicing \& chaired NPC Sc Economics and Trade, Scientific Council of the high school of commerce (ESC- Algiers) as well as the Board \& Director of several national companies during nearly a decade, SAK Kaya currently provides several lessons under management sciences at ENSAM - Meknes. He has taught at various institutions including France, A. North. He is the author of 5 books \& numerous articles in management, finance \& SI. He also led a very active consulting career. 